\title{
Photoinhibition on natural ammonia oxidizers biofilm populations and implications for nitrogen uptake in stream biofilms
}

\author{
Stephanie N. Merbt, ${ }^{\text {a* }}$ Susana Bernal, Lorenzo Proia, Eugenia Martí, Emilio O. Casamayor* \\ Department of Continental Ecology, Integrative Freshwater Ecology Group, Centre for Advanced Studies of Blanes (CEAB- \\ CSIC), Blanes, Spain
}

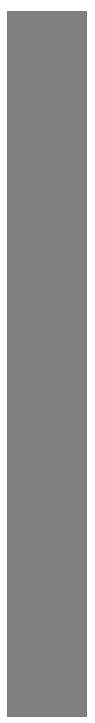

\begin{abstract}
We investigated photoinhibition on natural communities of ammonia oxidizing (AO) archaea (AOA) and bacteria (AOB) embedded in complex stream biofilms, and its implications on nitrogen uptake at biofilm scale. Based on the strong photoinhibition previously exhibited by free living and cultured AOA and AOB, we expected AO activity to decrease in biofilms experimentally exposed to light, reducing the contribution of microbial nitrification to ammonium uptake. To test it, we conducted light manipulation experiments in mesocosms using biofilms naturally developed on stream cobbles sides both exposed to light (light-side) and facing the sediment (dark-side). We observed a strong AO photoinhibition in dark-side biofilms, accompanied by either biofilm-scale decreases in nitrification or increases in nitrogen uptake likely by heterotrophic activity. Conversely, in light-side biofilms photoinhibition was not observed suggesting that photoautotrophic layers may protect $\mathrm{AO}$ in situ by a sunshade effect. Experimental light and dark alternation cycles stimulated $\mathrm{AO}$, enhancing both nitrification and ammonium uptake. These results support photoinhibition effects on natural AO communities, especially in biofilms developed under ambient dark conditions, whereas this effect seems to be buffered in biofilms developed under light conditions. Therefore, the contribution of nitrification to ammonium uptake at biofilm scale should consider not only the physiological study of AOA and AOB, but also the environmental conditions and community structure at the habitat microscale, since they may counterbalance, among others, the damaging light effects under natural conditions.
\end{abstract}

Microbial nitrification is a fundamental biogeochemical process in the global nitrogen $(\mathrm{N})$ cycle, connecting the reduced and oxidized forms of dissolved inorganic $\mathrm{N}$. The enzyme ammonia monooxygenase, present in both ammonia oxidizing archaea (AOA) and bacteria (AOB), catalyzes the first and rate limiting step of nitrification, the oxidation of ammonium $\left(\mathrm{NH}_{4}^{+}\right)$to nitrite $\left(\mathrm{NO}_{2}^{-}\right)$. For decades, it has been known that light completely inactivates activity of ammonia monooxygenase in $\mathrm{AOB}$ and de novo protein biosynthesis is required to recover activity (Schön and Engel 1962; Hyman and Arp 1992). Similarly, recent laboratory studies showed evidence of high susceptibility to light in AOA (French et al. 2012; Merbt et al. 2012), although the biochemical mechanisms associated with photoinhibition are still unknown (but see, Walker et al. 2010; Blainey et al. 2011). In this sense, the environmental distribution of $\mathrm{AO}$; and therefore, the potential for ammonia oxidation, has

*Correspondence: steffimerbt@gmail.com and casamayor@ceab.csic.es

apresent address: Eawag-Swiss Federal Institute of Aquatic Science and Technology, Department of Environmental Toxicology, Dübendorf, Switzerland been widely monitored in situ surveying the amoA gene encoding the alpha subunit of the enzyme ammonia monooxygenase in both bacteria and archaea (Fernàndez-Guerra and Casamayor 2012; Prosser and Nicol 2012).

Photoinhibition of ammonia oxidizers may be one of the reasons for the spatial distribution of $\mathrm{AOA}$ and $\mathrm{AOB}$ found in aquatic environments, and therefore for the spatial patterns of nitrification, with further implications on the dynamics of dissolved inorganic nitrogen (DIN) at ecosystem scale. For instance, in oceans and lakes, a greater accumulation of free living $\mathrm{AO}$ has been detected with decreasing light intensities (Church et al. 2010; Restrepo-Ortiz et al. 2014; Ortiz-Alvarez and Casamayor 2016) and frequently nitrification rates are higher at the interface between the euphotic and aphotic zone than in surface waters (Beman et al. 2012; Small et al. 2013). Similarly in eutrophic rivers, increases in nitrification and lack of photoautotrophic $\mathrm{N}$ uptake have been associated with water turbidity (Lipschultz et al. 1985). Alternatively, the observed spatial segregation may also be caused by competition for $\mathrm{NH}_{4}^{+}$between photoautotrophs and AO (Smith et al. 2014). Therefore, a clear 
link between light and the activity of $\mathrm{AO}$ in natural environments is still lacking.

In streams, AO develop on benthic substrata (e.g., Herrmann et al. 2011; Merbt et al. 2011) in association with other microorganisms forming three dimensional complex biofilm structures (Lock et al. 1984). Biofilms mostly relay on dissolved nutrients present in water, becoming hot spots of $\mathrm{N}$ uptake at reach scale (O'Brien and Dodds 2008; Ribot et al. 2013). The uptake of $\mathrm{NH}_{4}^{+}$is driven by both assimilatory (mostly by algae and heterotrophs) and dissimilatory (i.e., nitrification) processes, that contribute differentially depending on both biofilm microbial composition and environmental conditions (Teissier et al. 2007; Herrmann et al. 2011). Nitrification rates strongly vary among streams (Peterson et al. 2001), but they are especially relevant in $\mathrm{N}_{-} \mathrm{NH}_{4}^{+}$ enriched streams such as those influenced by waste water treatment plants (WWTP) effluents, where nitrification can contribute up to $70 \%$ of total $\mathrm{NH}_{4}^{+}$uptake (Merseburger et al. 2005; Ribot et al. 2012). Interestingly, in these highly $\mathrm{N}$ loaded streams, former studies had found high abundances of AO in natural biofilms developing under dark conditions on the cobbles side facing the sediment (Merbt et al. 2011). This observation suggested that light could shape the spatial distribution of AO in stream biofilms as already proposed in other freshwater environments (e.g., Restrepo-Ortiz et al. 2014).

The present study aimed to probe photoinhibition on $\mathrm{AO}$ present in naturally developed epilithic stream biofilms and its implications for $\mathrm{N}$ uptake. We hypothesized a major inhibitory effect on the activity of the enzyme ammonia monooxygenase after biofilms were experimentally exposed to light accompanied by a decrease of nitrification. To test it, we carried out light manipulation experiments in recirculating chambers using biofilms naturally developed on stream cobbles. We experimentally estimated $\mathrm{N}$ uptake and contribution of nitrification to $\mathrm{NH}_{4}^{+}$uptake and analyzed transcript and gene abundance of amoA of AOA and AOB using quantitative polymerase chain reaction (qPCR). The experiments were carried out with four biofilm types that developed on the light-side or dark-side of the cobbles (Fig. 1) from stream sites located upstream and downstream of a WWTP effluent input.

\section{Material and methods}

\section{Sampling site and sample description}

We selected two contiguous sites in La Tordera River (NE, Spain) located $50 \mathrm{~m}$ upstream (hereafter referred as "upstream site") and $900 \mathrm{~m}$ downstream (hereafter referred as "downstream site") of the incoming $\mathrm{NH}_{4}^{+}$rich effluent from the WWTP of Santa Maria Palautordera $\left(41^{\circ} 41^{\prime} 3.47^{\prime \prime} \mathrm{N}\right.$; $\left.2^{\circ} 27^{\prime} 33.19^{\prime \prime} \mathrm{W}\right)$. The light availability was similar at both sampling sites due to similar canopy cover, however mean $\mathrm{N}-\mathrm{NH}_{4}^{+}$concentration $(0.03 \pm 0.01$ vs. $7.26 \pm 0.28 \mathrm{mg} \mathrm{N}-$

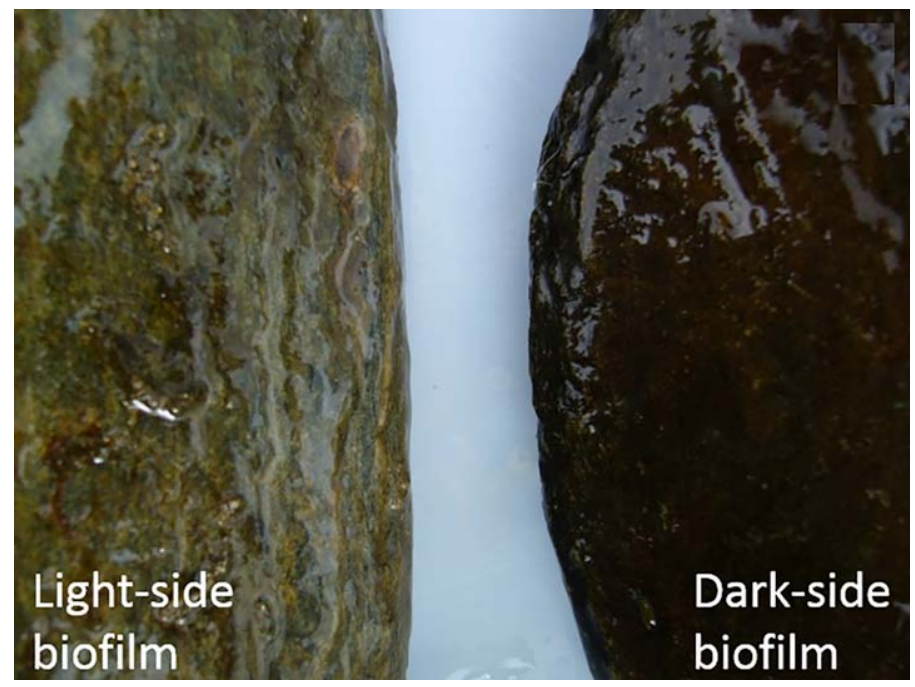

Fig. 1. Fresh biofilms naturally developed on the light-side and the dark-side of stream cobbles. [Color figure can be viewed at wileyonlinelibrary.com]

$\mathrm{NH}_{4}^{+} \mathrm{L}^{-1}$ ) differed by two orders of magnitude. Previous studies have shown substantial differences in both community composition and relative abundance of epilithic AOA and $\mathrm{AOB}$ between the upstream and downstream site. At the upstream site, AOB were barely detected and AOA was dominated by Nitrososphaera and Nitrosopumilus cluster. At the downstream site, AOB were dominated by Nitrosomonas oligotropha, Nitrosomonas communis, and Nitrosospira spp while AOA was dominated by Nitrosotalea devanaterra (Merbt et al. 2015). In January 2013, we collected fist sized cobbles that were naturally colonized by biofilms from the upstream and downstream sites. We selected cobbles that were submerged but not embedded into the sediment to replicate similar in situ oxygen and nutrient conditions for biofilms facing upwards (hereafter referred as "light-side biofilm") and toward the sediment (hereafter referred as "dark-side biofilm," Fig. 1). After collection, cobbles were carefully transported to the laboratory and immediately submerged in stream water.

During the experiments, we used light-side and dark-side biofilms separately taking advantage of the fact that both biofilm communities developed under the same environmental conditions except for light availability, which differed strongly between the two sides. Consequently, algae growth was mostly observed in light-side biofilms (Merbt et al. 2011, 2015, which induced the development of two distinct biofilm communities (Fig. 1). However, despite large differences in light availability and abundance of photoautotrophs, light-side and dark-side biofilms from a given location hosted similar AOA community composition (Merbt et al. 2015). Based on these findings, we assumed that differences observed during incubation experiments between 
Table 1. Codification of the experimental treatments carried out to test the effect of light on epilithic stream biofilms. Each experiment consisted in $12 \mathrm{~h}$ of pre-spike incubation phase followed by a spike of $\mathrm{N}-\mathrm{NH}_{4}^{+}$in the water and $8 \mathrm{~h}$ post-spike phase. The $\mathrm{N}-\mathrm{NH}_{4}^{+}$spike was used to measure potential $\mathrm{NH}_{4}^{+}$ consumption by biofilms and concomitant changes in water DIN concentrations (see text for details). The LL and DD treatments were applied to both upstream and downstream biofilms. The LD and DL treatments were carried out exclusively with downstream biofilms.

\begin{tabular}{lcc}
\hline & \multicolumn{2}{c}{ Light conditions } \\
\cline { 2 - 3 } Code & Pre-spike & Post-spike \\
\hline DD & $(\mathbf{1 2} \mathbf{~ h})$ & $(\mathbf{8} \mathbf{~})$ \\
LL & Dark & Dark \\
LD & Light & Light \\
DL & Light & Dark \\
\hline
\end{tabular}

biofilms from the two sides of the cobbles for a given location were related to their physiological response to light conditions rather than to differences in the composition of $\mathrm{AO}$ communities.

\section{Experimental setting}

To evaluate the physiological response of epilithic biofilms to light exposure, we carried out a set of replicated experiments using recirculating incubation chambers separately for the four types of biofilms. The experiments were run under the assumption that the composition of AO community in biofilms was determined by the location (either upstream vs. downstream) and orientation (either facing up or down) of the cobbles in the stream and that experimental light treatment would not cause community shifts during the incubation time.

For experiments targeting biofilms from the light-side of the cobbles, we carefully removed the biofilm from the darkside by scratching the surface with a sterile metal brush. We performed repeated washing steps with sterile distilled water followed by carefully dipping the scraped side in $70 \%$ ethanol for $10 \mathrm{~s}$, and a final water washing step. To run experiments only with biofilms from the dark-side of the cobbles a similar protocol was followed scratching the natural biofilm developed on the light-side. We placed 3-4 cobbles with the preserved biofilm side facing upwards in transparent methacrylate chambers $(30 \times 30 \times 10 \mathrm{~cm})$ for each experimental treatment. Chamber were filled with $8 \mathrm{~L}$ of stream water from the same site were cobbles were collected. Continuous water recirculation was carried out with a submergible peristaltic pump $(24 \mathrm{~V})$ at constant temperature $\left(21^{\circ} \mathrm{C}\right)$. For light exposure treatments, we used four LED light panels (Led's Grow $120 \mathrm{~W}$ V.2) at $100 \mu \mathrm{E} \mathrm{m}^{-2} \mathrm{~s}^{-1}$, intensity enough to strongly inhibit AO growth in batch cultures (Merbt et al.
2012). Each treatment was run in triplicates (three independent chambers each) and negative controls (stream water alone) in duplicates.

The experiments consisted of an initial biofilm acclimatization phase for $12 \mathrm{~h}$ (here after referred as "pre-spike phase") that aimed to allow biofilms to adapt to both the chambers and the given light conditions (either dark or light) followed by a spike of $\mathrm{N}^{-} \mathrm{NH}_{4}^{+}$and $8 \mathrm{~h}$ of incubation (here after referred as "post-spike phase") to measure the rates of $\mathrm{N}_{-} \mathrm{NH}_{4}^{+}$uptake, nitrification and net changes in DIN in the water. For each biofilm type, we run four experimental treatments where biofilms were exposed to different light (L) and dark (D) conditions during the pre-spike and postspike phases (Table 1). In the dark-dark (DD) treatment, prespike and post-spike phases were both carried out in the dark. We assumed that DD offered the best condition for nitrification, and therefore results from DD treatment were used as reference to evaluate potential optimal nitrification. In the light-light (LL) treatment, both pre-spike and postspike phase were carried out in the light, and aimed to evaluate potential photoinhibition effects when results were compared to those from DD treatment. In the dark-light (DL) treatment pre-spike phase was hold in dark and postspike phase in the light aiming to measure the resistance of $\mathrm{AO}$ to light (in this case, if biofilms were insensitive to light exposure). We considered that similar AO activity in the DD and DL treatments would indicate resistance of AO to photoinhibition. The light-dark (LD) treatment consisted of the pre-spike phase in the light and the post-spike phase in the dark to examine the resilience of $\mathrm{AO}$ to light (in this case, ability of biofilms to recover from light exposure). We considered that similar AO activity in the DD and LD treatments would indicate fast recovery of AO activity from photoinhibition. The DL and LD treatment were only carried out with epilithic biofilms from the downstream site for which AO activity and nitrification rates were expected to be the highest (Merseburger et al. 2005).

\section{Biofilm characterization}

Once each incubation period ended, the content of chlorophyll $a$ (Chl $a$, in $\mu \mathrm{g} \mathrm{cm}^{-2}$ ) was directly measured in the biofilms using a Bentotorch (BBE, Germany) (three measurements per cobble). Afterwards, biofilms were scraped from the cobbles with a sterile metallic brush. One biofilm composite sample per chamber was obtained and treated as an independent replicate. The total surface scraped was estimated by a weight-to-area relationship after covering the cobbles surface with aluminum foil. Biofilm ash free dry mass (AFDM, in $\mathrm{g} \mathrm{m}^{-2}$ ) was estimated as a proxy of biofilm biomass as previously reported (Merbt et al. 2011).

To analyze standing stock and transcriptional activity of $\mathrm{AOA}$ and $\mathrm{AOB}$ after the treatments we amplified the amoA gene of both, AOA and $\mathrm{AOB}$ in the genomic DNA and mRNA, respectively. Therefore, $1 \mathrm{~mL}$ RTL buffer (Quiagen) 
Table 2. Chl a content, biomass (AFDM), and abundance of AOA and AOB (mean \pm standard error) in biofilms developed on the light-side and dark-side of cobbles collected from the upstream $(n=6)$ and downstream $(n=12)$ sites. For each variable, different letters indicate statistically significant differences among biofilm types $(p<0.05$, one-way ANOVA followed by Tukey HSD post-hoc test). $F$ and $p$ values are shown.

\begin{tabular}{|c|c|c|c|c|c|c|c|}
\hline & Unit & \multicolumn{2}{|c|}{ Upstream } & \multicolumn{2}{|c|}{ Downstream } & $p$ & $F$ \\
\hline Chl $a$ & $\mu \mathrm{g} \mathrm{cm}^{-2}$ & $9.2 \pm 1.9^{\mathrm{a}}$ & $0.1 \pm 0.05^{b}$ & $7.9 \pm 0.7^{a}$ & $0.5 \pm 0.2^{b}$ & $<0.0001$ & 60 \\
\hline $\mathrm{AOA}$ & $10^{4}$ copies $\mathrm{cm}^{-2}$ & $6.3 \pm 2.3^{a}$ & $0.7 \pm 0.6^{b}$ & $0.5 \pm 0.3^{b}$ & $0.3 \pm 0.1^{b}$ & 0.015 & 4.8 \\
\hline $\mathrm{AOB}$ & $10^{4}$ copies $\mathrm{cm}^{-2}$ & $2.6 \pm 0.3^{\mathrm{a}}$ & $0.5 \pm 0.4^{b}$ & $134 \pm 23^{c}$ & $157 \pm 60^{c}$ & $<0.0001$ & 29.2 \\
\hline
\end{tabular}

containing $10 \mu \mathrm{L}$ B-Mercaptoethanol was added on the sampled biofilms and were immediately frozen in a 96\% ethanol bath at $-80^{\circ} \mathrm{C}$ and stored at $-80^{\circ} \mathrm{C}$. RNA and DNA were extracted using MOBIO RNA power soil and DNA accessory kit (MOBIO Laboratories), respectively, following the manufacturer's instructions. Extracted nucleic acids were quantified with Qubit fluorometer (Invitrogen). The RNA extract was treated with Dnase AMBION Turbo DNA free to digest carry over DNA (Invitrogen). cDNA was synthesized from 10 ng of RNA with random hexamer primers (160 pmol per reaction) using Superscript II reverse transcriptase (Bio-Rad). Two negative controls were carried out along the process. The first control contained all DNase/RT reagents and the RNA template but lack RT enzyme, to confirm that the RNA extract was DNA free. The second control combined all DNase/RT reagents but no RNA template (water only) to check for reagents contamination (Nicol et al. 2008).

The abundances of amoA gene and cDNA were estimated by quantitative real-time polymerase chain reaction (qPCR). The qPCR assays were carried out as previously described (Merbt et al. 2011). Briefly, AOB were targeted by the primers amoA-1F (59-GGGTTTCTACTGGTGGT-39) and amoA-2R (59-CCCCTCKGSAAAGCCTTCTTC-39) that generated a 491 base-pair (bp) fragment (Rotthauwe et al. 1997). AOA were targeted by the primer sets CrenamoA23f (59ATGGTCTGGCTWAGACG-39) and CrenamoA616r (59GCCATCCATCTGTATGTCCA-39) that amplified a 628- bp fragment (Tourna et al. 2008). Quantification was run in a final volume of $10 \mu \mathrm{L}$ containing a $5 \mu \mathrm{L}$ solution of SsoFast EvaGreen supermix (Bio-Rad), $1 \mathrm{ng}$ of template genomic DNA and 2-3 ng of cDNA, $200 \mathrm{nmol} \mathrm{L}^{-1}$ of each corresponding primer, $0.3 \mathrm{mg} \mathrm{mL}^{-1} \mathrm{BSA}$, and molecular biology-grade water (Sigma), using a DNA Engine thermal cycler equipped with a Chromo 4 Real-Time Detector (Bio-Rad, Hercules). The cycling included an initial denaturation step of 2 min at $98^{\circ} \mathrm{C}$, followed by 45 cycles of denaturation for $5 \mathrm{~s}$ at $98^{\circ} \mathrm{C}$, annealing for $20 \mathrm{~s}$ at $57^{\circ} \mathrm{C}$ and $58^{\circ} \mathrm{C}$ for $\mathrm{AOA}$ and $\mathrm{AOB}$ respectively, and elongation for $15 \mathrm{~s}$ at $72^{\circ} \mathrm{C}$. After cycling, a 1 min denaturation hold at $95^{\circ} \mathrm{C}$ was included followed by 1 min at $65^{\circ} \mathrm{C}$ to guarantee a stringent coupled PCR product.
All qPCR runs were double checked on amplicon specificity by applying a melting curve from $55^{\circ} \mathrm{C}$ to $95^{\circ} \mathrm{C}$ and by agarose gel electrophoresis. Each run was compared with a standard curves from $10^{7}$ to $10^{2}$ copies $\mu \mathrm{L}^{-2}$ of amoA DNA from an available environmental clone. qPCR data were kept when run efficiency ranged from $85 \%$ to $110 \%$. Controls without templates resulted in undetectable values and no unspecific PCR products such as primer dimers or gene fragments of unexpected length were observed.

We calculated the ratio between abundance of RNA and DNA to standardize for differences in amoA gene abundance among sampling sites and biofilm types. The RNA : DNA ratio was considered as a proxy of the transcriptional activity (Lipsewers et al. 2014).

\section{Biofilm $\mathrm{NH}_{4}^{+}$uptake and nitrification rates}

To measure both $\mathrm{NH}_{4}^{+}$uptake and nitrification rates in the chambers, the concentration of $\mathrm{N}_{-} \mathrm{NH}_{4}^{+}$in the water was increased by 2-5 times by adding a spike of $\mathrm{NH}_{4} \mathrm{Cl}$. Then, we measured $\mathrm{N}-\mathrm{NH}_{4}^{+}, \mathrm{N}-\mathrm{NO}_{2}^{-}$, and $\mathrm{N}_{-} \mathrm{NO}_{3}^{-}$concentrations in water samples $(60 \mathrm{~mL})$ collected at $2,30,60,120,180,240$, 300,390 and $480 \mathrm{~min}$ after the spike. Samples were immediately filtered through a glass fiber filter (FVF, $0.7 \mu \mathrm{m}$ nominal pore size) and stored at $-20^{\circ} \mathrm{C}$ until colorimetric analyses (APHA 1995). Temperature, electrical conductivity, $\mathrm{pH}$, and dissolved oxygen (DO) concentration were frequently recorded and did not substantially change during the incubations.

We used the variation in $\mathrm{N}_{-} \mathrm{NH}_{4}^{+}$concentration in the water column over the incubation time to estimate the $\mathrm{NH}_{4}^{+}$ uptake rate $\left(k_{\mathrm{NH}_{4}}\right.$, in $\left.\mathrm{mg} \mathrm{N} \mathrm{L}^{-1} \mathrm{~h}^{-1}\right)$ following the equation:

$$
k_{\mathrm{NH}_{4}}=\frac{C_{t}-C_{0}}{t}
$$

where $t$ is time (in $\mathrm{h}$ ), and $C_{0}$ and $C_{t}$ are the concentrations of $\mathrm{N}_{-} \mathrm{NH}_{4}^{+}$at time zero (i.e., 2 min after the spike) and at consecutive incubation times, respectively $\left(\mathrm{mg} \mathrm{L}^{-1}\right)$ (Mußmann et al. 2013). Note that values of $k_{\mathrm{NH} 4}>0$ indicate decrease in $\mathrm{N}^{-} \mathrm{NH}_{4}^{+}$concentration in the water column, which denotes $\mathrm{NH}_{4}^{+}$uptake. A similar mathematical approach was used for calculating the nitrification rate $\left(k_{\mathrm{NIT}}\right.$ 
in $\mathrm{mg} \mathrm{N} \mathrm{L}^{-1} \mathrm{~h}^{-1}$ ), which was derived from the variation of either $\mathrm{N}_{-} \mathrm{NO}_{3}^{-}$or $\mathrm{N}-\mathrm{NO}_{2}^{-}$concentrations in the water column during the incubation time. Note that values of $k_{\mathrm{NIT}}>0$ indicate an increase of either $\mathrm{N}_{-} \mathrm{NO}_{3}^{-}$or $\mathrm{N}_{-} \mathrm{NO}_{2}^{-}$concentrations in the water column, which denotes the occurrence of nitrification. The incubations of upstream biofilms showed small changes in $\mathrm{N}^{-\mathrm{NO}_{3}^{-}}$concentration over time likely because the abundance of $\mathrm{NO}_{2}^{-}$oxidizing bacteria was extremely low as previously reported (Mußmann et al. 2013). For upstream biofilms the $k_{\mathrm{NH} 4}$ and $k_{\mathrm{NIT}}$ rates were calculated considering only $180 \mathrm{~min}$ of post-spike incubation because after this time $\mathrm{N}-\mathrm{NH}_{4}^{+}$concentration in the water column was under detection level. For downstream biofilms the $k_{\mathrm{NH} 4}$ and $k_{\mathrm{NIT}}$ rates were calculated considering the full post-spike incubation time (480 min). Values of $k_{\mathrm{NH} 4}$ and $k_{\mathrm{NIT}}$ were set to zero when the linear regression was not significant $(p>0.05)$.

We assessed the relative importance of nitrification in the chambers for the different treatments using the $k_{\mathrm{NIT}}: k_{\mathrm{NH} 4}$ ratio (as a proxy of the contribution of nitrification to the measured $\mathrm{NH}_{4}^{+}$uptake) together with the estimation of the net change in DIN concentration during the incubation $(\Delta \mathrm{DIN}$, in $\%$ ) based on the equation:

$$
\Delta \mathrm{DIN}=100 \times\left[\left(\frac{\mathrm{DIN}_{\mathrm{f}}}{\mathrm{DIN}_{\mathrm{o}}}\right)-1\right]
$$

where $\operatorname{DIN}_{\mathrm{f}}$ and $\mathrm{DIN}_{\mathrm{o}}$ are the final and initial DIN concentration (in $\mathrm{mg} \mathrm{L}^{-1}$ ) in the water column, respectively. Values of $\Delta \mathrm{DIN}<0$ indicate net removal of DIN in the water column during the incubation, whereas values of $\Delta \mathrm{DIN}>0$ indicate net production of DIN. We considered that $\Delta \mathrm{DIN} \sim 0$ and $k_{\mathrm{NIT}}: k_{\mathrm{NH}_{4}} \sim 1$ indicated that $\mathrm{NH}_{4}^{+}$uptake in the chambers was mostly driven by nitrification. This scenario does not imply the absence of $\mathrm{NH}_{4}^{+}$mineralization or assimilatory $\mathrm{NH}_{4}^{+}$uptake during the incubation, but that the magnitude of these processes might not be large enough to result in net changes in DIN concentration or $k_{\mathrm{NIT}}: k_{\mathrm{NH}_{4}} \neq 1$. We considered that $\Delta \mathrm{DIN}>0$ and $k_{\mathrm{NIT}}: k_{\mathrm{NH}_{4}} \geq 1$ showed the occurrence of indirect nitrification (from mineralized $\mathrm{NH}_{4}^{+}$) during the incubation experiment. Finally, we considered that $\Delta \mathrm{DIN}<0$ and $k_{\mathrm{NIT}}: k_{\mathrm{NH}_{4}}<1$ indicated that nitrification, if occurring, may be offset by assimilatory $\mathrm{NH}_{4}^{+}$uptake.

\section{Statistical analysis}

Differences in AFDM, Chl $a$ content, and AOA and AOB genes abundances among the biofilm types were tested with one-way ANOVA followed by a Tukey HSD post-hoc test. The test was run using ln-transformed values to fit normality requirements (Zar 1996). We examined the effect of light on AOA and AOB activity (RNA : DNA ratio), $\mathrm{NH}_{4}^{+}$uptake and nitrification rates $\left(k_{\mathrm{NH}_{4}}\right.$ and $k_{\mathrm{NIT}}$, respectively), $k_{\mathrm{NIT}}: k_{\mathrm{NH}_{4}}$ ratio and $\triangle \mathrm{DIN}$ by comparing data from the DD and LL treatments with a Kruskal-Wallis test. A non-parametric test was chosen because not all the data sets were normally distributed. Finally, we used a one-way ANOVA followed by a
Tukey HSD post-hoc test to examine differences in AOA and AOB activity (RNA : DNA ratio), $\mathrm{N}$ processing rates $\left(k_{\mathrm{NH}_{4}}\right.$ and $k_{\mathrm{NIT})}, k_{\mathrm{NIT}}: k_{\mathrm{NH}_{4}}$ ratio and $\Delta \mathrm{DIN}$ among the DD, DL, and LD treatments. To run statistical analysis, we considered that $a m o A$ transcript abundance equaled half of the minimum detected value (i.e., 30 and 5 transcripts $\mathrm{cm}^{-2}$ for AOA and $A O B$, respectively) when transcripts were below the detection limit. All statistical tests were carried out using R Foundation for Statistical Computing (2014, Vienna, Austria; http:// www.R-project.org).

\section{Results}

\section{Biofilms characterization}

Consistent differences were observed in biomass (i.e., AFDM), Chl $a$ content and AO abundance among the different biofilm types. As expected, Chl a concentrations were higher in biofilms on the light-side than on the dark-side of the cobbles. The upstream biofilm showed higher AFDM in the light-side than in the dark-side of the cobbles, while no AFDM differences between sides were observed downstream (Table 2). In the upstream biofilms, both AOA and AOB were more abundant in light-side than in dark-side biofilms, while no significant differences were observed in downstream biofilms. Interestingly, AOA were more abundant upstream, whereas the abundance of $\mathrm{AOB}$ was 100-fold higher downstream (Table 2).

\section{Light influence on amoA genes transcription}

Results from the DD treatment showed that after the incubations normalized transcription of AOB-amoA gene (expressed as RNA : DNA ratio) was higher in biofilms from downstream than upstream (Fig. 2A). Conversely, normalized transcription of AOA-amoA genes was only detected in upstream biofilms (Fig. 2B). Remarkably the RNA : DNA ratio for $\mathrm{AOB}$ in downstream biofilms was 80-fold higher than the ratio for AOA in upstream biofilms. On average, normalized transcription of amoA gene was 13-fold higher in dark-side than in light-side biofilms (Fig. 2, panels A and B).

In light-side biofilms normalized transcription of AOAamo $A$ and AOB-amoA gene was similar both in dark (DD) and in full light (LL) treatments. Conversely, in dark-side biofilms normalized transcription of amoA gene significantly decreased when exposed to the light treatment (LL) in both, AOA and AOB. In particular, normalized transcription of AOB-amoA genes in dark-side biofilms from the downstream site was on average 90\% lower in LL than in DD while normalized transcription of AOA-amoA genes in biofilms from the upstream site was below detection limit when exposed to light (Fig. 2, panels A and B). Normalized transcription of AOB-amoA genes in biofilms from the downstream site was higher after biofilms were exposed to light cycles (DL and LD treatments) than in the DD treatment (Fig. 3, panel A). 

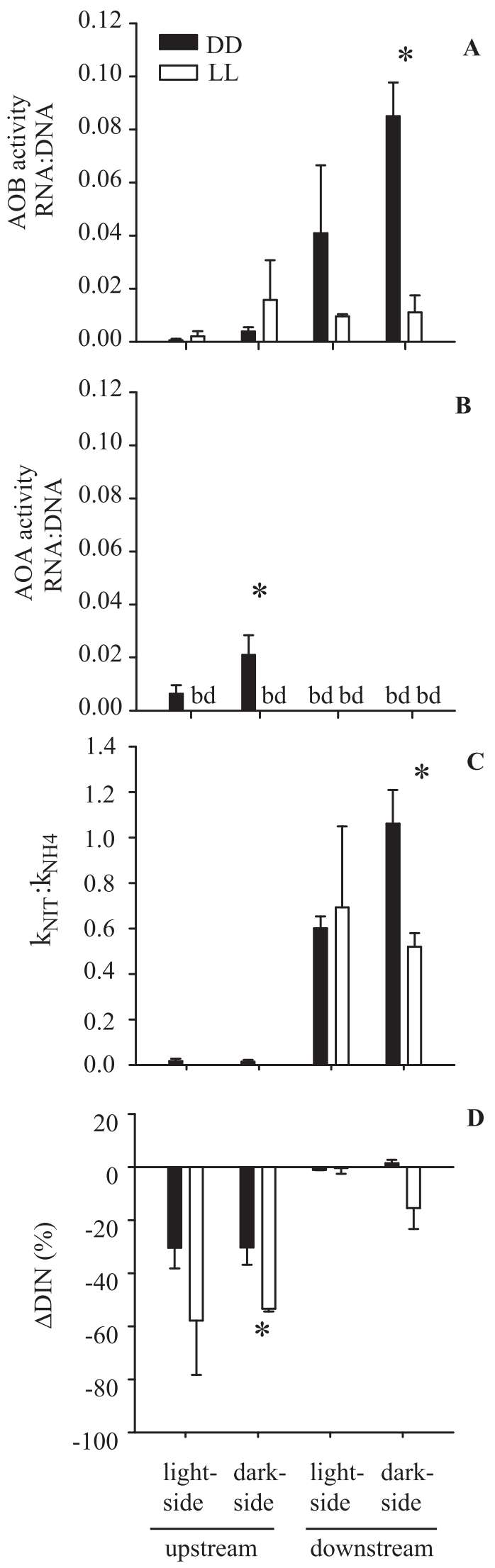

Light influence on biofilm $\mathrm{NH}_{4}^{+}$uptake and nitrification rates

In the $\mathrm{DD}$ treatments, $\mathrm{N}-\mathrm{NH}_{4}^{+}$concentration in water decreased over time after the $\mathrm{N}_{-} \mathrm{NH}_{4}^{+}$spike in the chambers for all biofilm types (Fig. 4 ). The resulting $k_{\mathrm{NH} 4}$ ranged from 0.16 to $0.29 \mathrm{mg} \mathrm{N} \mathrm{L}^{-1} \mathrm{~h}^{-1}$ (Table 3). The incubations of upstream biofilms showed small increases in $\mathrm{N}_{-} \mathrm{NO}_{2}^{-}$concentration after the $\mathrm{N}^{-\mathrm{NH}_{4}^{+}}$spike, while a marked increase in $\mathrm{N}$ $\mathrm{NO}_{3}^{-}$concentration was observed in the incubations of downstream biofilms (Fig. 4). This contrasting pattern in $\mathrm{NO}_{\mathrm{x}}^{-}$production resulted in $k_{\mathrm{NIT}}$ values 100 -fold higher for biofilms from downstream than upstream sites (Table 3). Upstream biofilms showed very low $k_{\mathrm{NIT}}: k_{\mathrm{NH}_{4}}$ ratios and negative values for $\Delta \mathrm{DIN}$. In contrast, downstream biofilms showed $k_{\mathrm{NIT}}: k_{\mathrm{NH}_{4}}$ ratios $>0.6$ and $\Delta \mathrm{DIN}$ values close to zero (Fig. 2, panels $\mathrm{C}$ and $\mathrm{D}$, respectively).

In the LL treatments, both $k_{\mathrm{NH}_{4}}$ and $k_{\mathrm{NIT}}$ were similar (or differences only marginally significant) to those in DD treatments. The exception was for the light-side biofilms upstream that showed lower $k_{\mathrm{NIT}}$ when exposed to light (Table 3 ). The $k_{\mathrm{NIT}}: k_{\mathrm{NH}_{4}}$ ratio decreased by half when darkside biofilms from the downstream site were exposed to light, whereas $\triangle \mathrm{DIN}$ decreased by $57 \%$ for dark-side biofilms from the upstream site (Fig. 2, panels $C$ and D). For the light-side biofilms from the two stream sites, differences in $k_{\mathrm{NIT}}: k_{\mathrm{NH}_{4}}$ and $\Delta \mathrm{DIN}$ between the LL and DD treatments were not significant.

In the DL and LD treatments, $k_{\mathrm{NH}_{4}}$ was similar to that measured in the DD treatment for dark-side biofilms, whereas light-side biofilms showed higher $k_{\mathrm{NH}_{4}}$ in DL and LD treatments than in the DD treatment (Table 4 ). The two biofilm types from the downstream site showed $k_{\text {NIT }}$ values significantly lower in DL than in DD treatment, while $k_{\mathrm{NIT}}$ values were significantly higher in LD than in DD treatment only for the light-side biofilm (Table 4). Both $k_{\mathrm{NIT}}: k_{\mathrm{NH}_{4}}$ and $\triangle \mathrm{DIN}$ values were lower in the DL than in the DD treatment for the two types of biofilm, and $\triangle \mathrm{DIN}$ was lower in LD than in DD treatment in the light-side biofilm (Fig. 3, panel B and C). No additional differences were observed for the remaining combinations.

\section{Discussion}

The inhibitory effect of light on AO has been well documented for laboratory cultures (Hooper and Terry 1974; Merbt et al. 2012) and recently reported for pelagic aquatic environments (Beman et al. 2012; Pedneault et al. 2014).

Fig. 2. Response of light-side and dark-side biofilms from upstream and downstream sites to dark (DD treatment, black bars) and light ( $L L$ treatment, white bars) experimental conditions. RNA : DNA ratios for AOB (A) and AOA (B), $k_{\mathrm{NIT}}: k_{\mathrm{NH} 4}$ ratio (C) and $\triangle \mathrm{DIN}(\mathbf{D})$ are shown. Mean and standard errors of three independent replicates. Asterisks show significant differences between DD and LL (Kruskal-Wallis test; $p<0.05$ ). bd, below detection limit. 

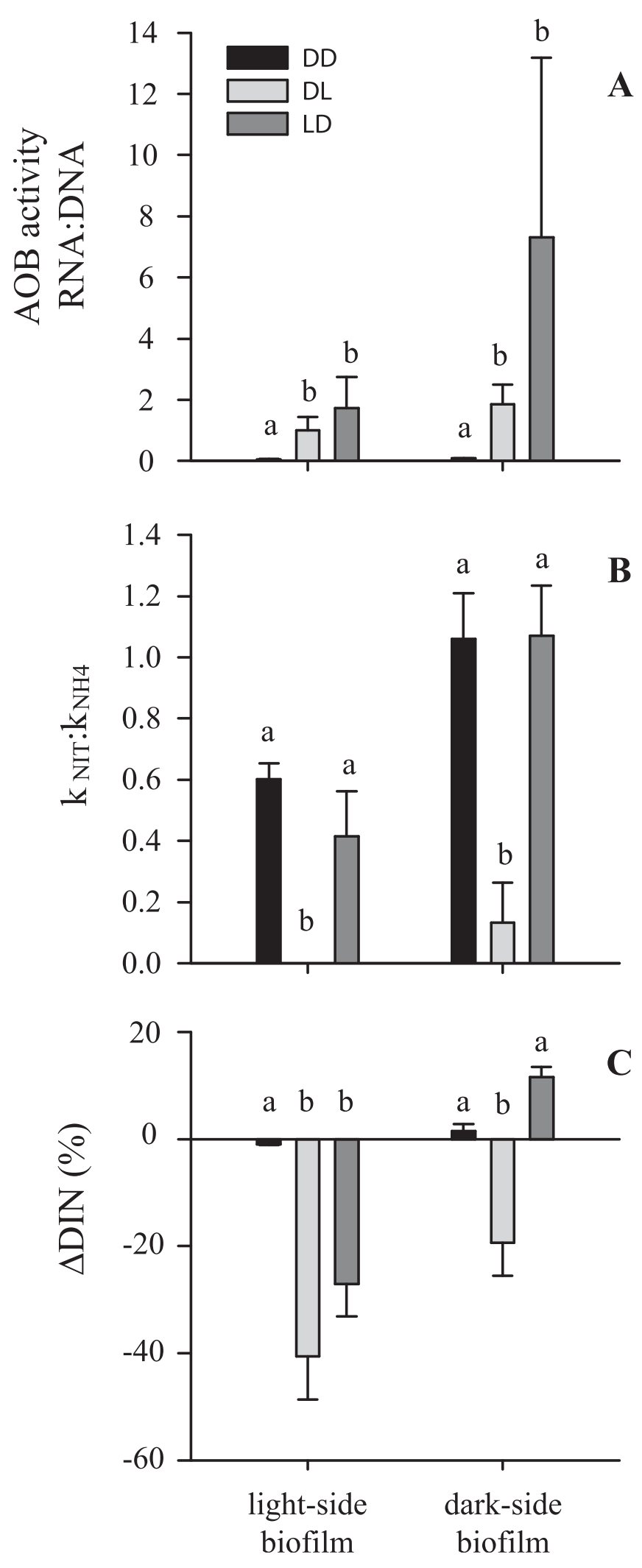

Our study shows that light can have a similar inhibitory effect (up to 100\%) on AOA and AOB in stream epilithic biofilms. Normalized amoA gene transcription was significantly reduced in biofilms naturally developed on the dark-side of the cobbles. Thus, photoinhibition was observed in AO communities that develop in biofilms that are not exposed to light in situ. Interestingly, AO in biofilms developed on the light-side of the cobbles showed lower sensitivity to the light treatments. Altogether, these results suggest that the response to intense light exposure of $\mathrm{AO}$ in stream biofilms can be modulated by the biofilm architecture, which can be influenced by habitat conditions where biofilms develop. Such habitat dependent response was similar for biofilms from both upstream and downstream sites and, hence, independent of the in situ environmental conditions, AO abundance and relative dominance of AOA or AOB.

The observed large differences of $\mathrm{AO}$ assemblages between biofilms from the upstream and downstream sites are in agreement with previous studies (Merbt et al. 2011, 2015); and AO abundances match with those found in biofilms growing in simulated creek systems under varying $\mathrm{N}_{-} \mathrm{NH}_{4}^{+}$ concentrations (Herrmann et al. 2011). Given that canopy cover was similar between the two sites and that cobbles were collected from well oxygenated riffle areas in both cases, divergences in the $\mathrm{AO}$ community between upstream and downstream sites were possibly due to the differences in $\mathrm{N}-\mathrm{NH}_{4}^{+}$availability and to the presence of allocthonous AOB (from the WWTP effluent) (Martens-Habbena et al. 2009; Mußmann et al. 2013; Sonthiphand et al. 2013). The high abundance of AOB in the downstream biofilms together with their higher normalized transcriptional activity were likely responsible for the high nitrification rates exhibited by these biofilms during the incubations, with $k_{\text {NIT }} 100$-fold higher than for biofilms collected at the upstream site. Moreover, the high stream $\mathrm{N}_{-} \mathrm{NH}_{4}^{+}$concentrations below the WWTP effluent possibly favored AOB colonization and sustained high nitrification rates (Strauss et al. 2002; Merseburger et al. 2005). Consequently, the relative contribution of nitrification to $\mathrm{NH}_{4}^{+}$uptake (i.e., $k_{\mathrm{NIT}}: k_{\mathrm{NH} 4}>0.6$ and $\Delta \mathrm{DIN}$ $\sim 0$ ) at biofilm scale at this site was high. Moreover, the clear differences in AO abundance, relative composition and normalized genes transcription at habitat scale (i.e., between biofilms developed at the two cobble sides at a given

Fig. 3. Response of light-side and dark-side biofilms from the downstream site to light switches in relation to their response to potential optimal conditions (DD treatment, black bars). Light gray bars show dark pre-incubation in darkness and $\mathrm{N}-\mathrm{NH}_{4}^{+}$spike incubation with light (DL). Dark gray bars show light pre-incubation and $\mathrm{N}-\mathrm{NH}_{4}^{+}$spike incubation in darkness (LD). Activity of AOB (A) as RNA : DNA ratio, $k_{\mathrm{NIT}}: k_{\mathrm{NH} 4}$ ratio $(\mathbf{B})$ and $\triangle \mathrm{DIN}(\mathbf{C})$ are shown. Mean and standard errors of three independent replicates. Different letters indicate statistical significant differences between light treatments (one-way ANOVA followed by a Tukey HSD post-hoc test). AOA activity below detection limit in all the cases (data not shown). 

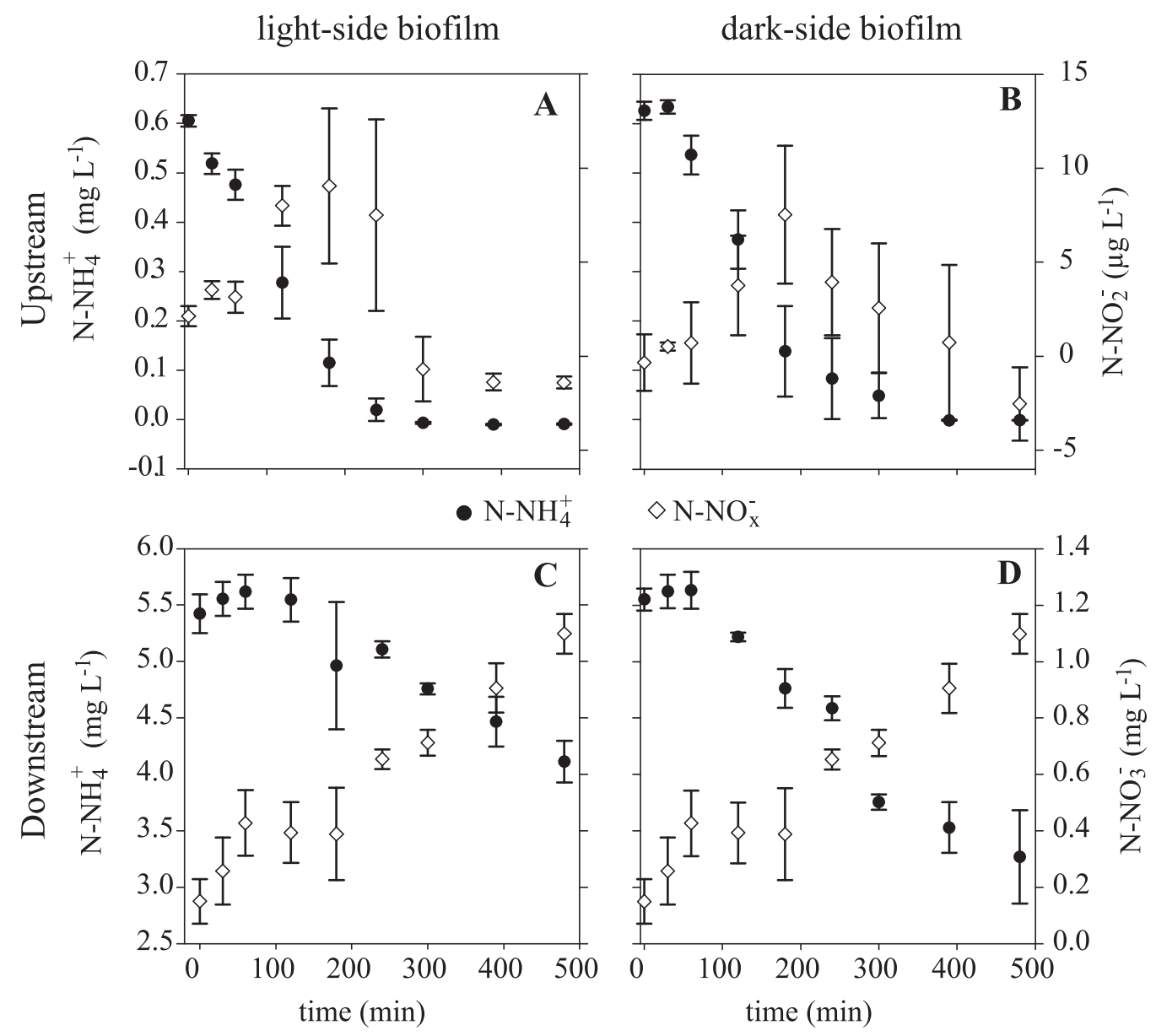

Fig. 4. Kinetics of $\mathrm{N}-\mathrm{NH}_{4}^{+}$and $\mathrm{N}-\mathrm{NO}_{x}^{-}$concentrations after the $\mathrm{N}-\mathrm{NH}_{4}^{+}$spike for the $\mathrm{DD}$ treatment chamber (potential optimal conditions) for lightside and dark-side biofilms collected from upstream (panels $\mathbf{A}$ and $\mathbf{B}$ ) and downstream sites (panels $\mathbf{C}$ and $\mathbf{D}$ ). Background concentrations measured prior to the $\mathrm{N}_{-} \mathrm{NH}_{4}^{+}$spike subtracted from the plots. Note differences in units scale for $\mathrm{N}-\mathrm{NO}_{\mathrm{x}}^{-}$between upstream and downstream sites.

location) further highlight that spatial heterogeneity can be relevant to understand whole-reach patterns of nitrification in streams.

Our results showed that the response of AO to light was also depending on their distribution at the habitat scale. In dark-side biofilms, AO are restricted to the first $50 \mu \mathrm{m}$, the oxic narrow zone of the biofilm matrix (Schramm et al. 1996; Gieseke et al. 2005). Thus, AO developed in these biofilms, which were not naturally exposed to light, were probably fully exposed to irradiance during light experimental treatments, explaining the remarkable decrease in the amo $A$ gene transcription. In contrast, light-side biofilms were dominated by photoautotrophic algae as evidenced by high Chl $a$ content and macroscopic aspect. Therefore, the first layer of the biofilm matrix is most likely colonized by algae that may provide shading and oxygen to AO located in deeper layers. Hence, the architecture of the light-side biofilm matrix itself could protect AO from light damage, and such putative sunshade effect could operate even under full light ambient exposure. In fact, a similar mechanism has been proposed to explain sustained photoautotrophic activity under high irradiance in streams (Boston and Hill 1991; Guasch and Sabater 1995). In this line of thought, previous investigations carried out in the same stream sites showed Nitrosotalea devanaterra-like as dominant AOA in both, lightside and dark-side biofilms (Merbt et al. 2015), a species strongly inhibited by light in experiments carried out in cultures (Merbt et al. 2012). This fact suggests that light avoidance was the most likely strategy to overcome photoinhibition in natural biofilms. Nevertheless, visualization of the 3D biofilm matrix including specific fluorescence in situ hybridization of the AO populations would be necessary to fully confirm this hypothesis (Gieseke et al. 2005).

The results from light cycles treatments (DL and LD treatments) suggest that AO in natural epilithic biofilms can develop strategies to cope with diurnal light changes, although not necessarily these are associated with AO resistance and recovery capacity. In fact, in light-side biofilms, amo $A$ transcription of $\mathrm{AOB}$ was higher in the DL and LD treatments than under fully dark conditions (i.e., DD 
Table 3. Rate coefficients of $\mathrm{NH}_{4}^{+}$uptake $\left(k_{\mathrm{NH} 4}\right)$ and nitrification $\left(k_{\mathrm{NIT}}\right)$ in the LL and DD treatment (mean \pm standard error) for light-side and dark-side biofilms collected from the upstream and downstream sites. $n=3$ in all cases. $p$ values of the Kruskal-Wallis tests are shown. ns, non- significant $(p>0.05)$.

\begin{tabular}{|c|c|c|c|c|c|}
\hline $\mathrm{mg} \mathrm{N} \mathrm{L}^{-1} \mathrm{~h}^{-1}$ & Treatment & \multicolumn{2}{|c|}{ Upstream } & \multicolumn{2}{|c|}{ Downstream } \\
\hline \multirow[t]{3}{*}{$k_{\mathrm{NH} 4}$} & DD & $0.16 \pm 0.02$ & $0.17 \pm 0.03$ & $0.18 \pm 0.02$ & $0.29 \pm 0.05$ \\
\hline & $\mathrm{LL}$ & $0.23 \pm 0.01$ & $0.30 \pm 0.05$ & $0.14 \pm 0.02$ & $0.32 \pm 0.02$ \\
\hline & $p$ value & 0.049 & 0.05 & ns & ns \\
\hline$k_{\mathrm{NIT}}$ & DD & $0.003 \pm 0.001$ & $0.002 \pm 0.001$ & $0.11 \pm 0.003$ & $0.30 \pm 0.04$ \\
\hline
\end{tabular}

Table 4. Rate coefficients of $\mathrm{NH}_{4}^{+}$uptake $\left(k_{\mathrm{NH} 4}\right)$ and nitrification $\left(k_{\mathrm{NIT}}\right)$ in the DD, DL, and LD treatments (mean \pm standard error) for light-side and dark-side biofilms from the downstream site $(n=3)$. For each biofilm type, different letters indicate statistical significant differences among light treatments $(p<0.05$, one-way ANOVA followed by a Tukey HSD post-hoc test). $F$ and $p$ values are shown. ns, non-significant $(p<0.05)$.

\begin{tabular}{llcc}
\hline & & \multicolumn{2}{c}{ Downstream } \\
\cline { 3 - 4 } $\mathbf{m g ~ N ~ L}^{-1} \mathbf{h}^{-1}$ & Treatment & $\begin{array}{l}\text { Light-side } \\
\text { biofilm }\end{array}$ & $\begin{array}{c}\text { Dark-side } \\
\text { biofilm }\end{array}$ \\
\hline$k_{\mathrm{NH} 4}$ & DD & $0.18 \pm 0.02^{\mathrm{a}}$ & $0.29 \pm 0.05$ \\
& DL & $0.55 \pm 0.08^{\mathrm{b}}$ & $0.41 \pm 0.10$ \\
& LD & $0.57 \pm 0.14^{\mathrm{b}}$ & $0.49 \pm 0.04$ \\
& $p$ value & 0.046 & $\mathrm{~ns}$ \\
$k_{\mathrm{NIT}}$ & $F$ & 5.403 & \\
& DD & $0.11 \pm 0.003^{\mathrm{a}}$ & $0.30 \pm 0.04^{\mathrm{ab}}$ \\
& DL & $0.07 \pm 0.07^{\mathrm{a}}$ \\
& LD & $0.20 \pm 0.04^{\mathrm{c}}$ & $0.53 \pm 0.09^{\mathrm{b}}$ \\
& $p$ value & 0.002 & 0.012 \\
& $F$ & 19.62 & 10.12 \\
\hline
\end{tabular}

treatment) suggesting that switches in light exposure act as a stimulus rather than a stressor of AO activity. This could be explained by the increase of oxygen concentration expected in deeper biofilm layers during day time as a result of the triggering effect of light on photosynthetic activity (Roeselers et al. 2008). In dark-side biofilms, for which photoinhibition was evident during continuous exposition to light $(20 \mathrm{~h}$ in LL treatment), amoA transcription of AOB was also higher for the DL and LD treatments than for the treatment under full dark conditions. This result suggests that matrix embedded AO have the ability to either resist or recover relatively fast (within $8 \mathrm{~h}$ ) after light damages, even when light is an unusual stressor for these biofilms. These observations agree with results from culture based studies showing that AOB have a fast recovery after light exposure (Guerrero and Jones 1996; Merbt et al. 2012).
The photoinhibition that $\mathrm{AO}$ assemblages experienced in dark-side biofilms from the downstream site was accompanied by a strong decline in $k_{\mathrm{NIT}}: k_{\mathrm{NH} 4}$, suggesting a tight link between transcriptional AO activity and the relative contribution of nitrification to $\mathrm{N}$ uptake at biofilm scale. This result nicely illustrates that the combination of molecular ecology and biogeochemistry can provide mechanistic explanations for the functioning of microbial communities and a better comprehension of the microbial contribution to stream nutrient fluxes (Smith et al. 2014; Vile et al. 2014). Nonetheless, the link between amoA genes transcription and nitrification rates was not so evident in the dark-side biofilms from the upstream site, likely because rates were under detection limits. Moreover, the observed light-induced increase in assimilatory $\mathrm{N}$ uptake suggests that other microbial components responded positively to light exposure. For instance, heterotrophs, which are major components of dark-side epilithic biofilms, can assimilate $\mathrm{NH}_{4}^{+}$and $\mathrm{NO}_{3}^{-}$ and thus, compete against $\mathrm{AO}$ for substrates (Verhagen and Laanbroek 1991; Kirchman 1994; Strauss and Lamberti 2000). A similar pattern was observed after $8 \mathrm{~h}$ of light exposure in the DL treatment, showing that microbial assemblages respond relatively fast (in the scale of a few hours) to changes in light conditions.

In contrast to dark-side biofilms, light-side biofilms contained high abundance of algae. Light enhances photosynthetic activity and algal $\mathrm{N}$ demand (Reuter et al. 1986), which can severely limit nitrification and bring AO to starvation in situ (Lipschultz et al. 1985; Risgaard-Petersen et al. 2004; Smith et al. 2014). Therefore, one would expect an increase in assimilatory DIN uptake, that is a decrease in both $\Delta \mathrm{DIN}$ and $k_{\mathrm{NIT}}: k_{\mathrm{NH} 4}$ ratios during experimental light exposure. However, the LL treatment showed similar $\Delta \mathrm{DIN}$ and $k_{\mathrm{NIT}}: k_{\mathrm{NH} 4}$ ratios than those measured during fully dark conditions (DD treatment), which could be partially explained by the depletion of other essential nutrients such as phosphate during the continuous exposition to light (Cullen et al. 1992). As expected, a substantial increase in assimilatory $\mathrm{N}$ uptake was observed under light cycles (DL 
and LD treatments), although the LD treatment showed concomitant increases in nitrification rates, and thus no changes in $k_{\mathrm{NIT}}: k_{\mathrm{NH} 4}$ rates compared to fully dark conditions. This finding indicates that the overall $\mathrm{N}$ processing at the biofilm scale was stimulated by the switch in light conditions, and further suggests that the presence of photoautotrophs can benefit AO activity likely because they provide both shade and oxygen in the biofilms. This finding, however, contrasts with the widely held idea that AO are outcompeted by algae in aquatic environments (Risgaard-Petersen et al. 2004; Smith et al. 2014). Interestingly, in the DL treatment nitrification rates dropped down to zero despite the increase in transcription for AOB activity. This fact may indicate that the $\mathrm{N}_{-} \mathrm{NO}_{3}^{-}$ produced was rapidly consumed by other co-existing microorganism, probably algae (Reuter et al. 1986). Together, these observations suggest that natural daily light cycles probably enhance $\mathrm{N}$ assimilation and nitrification in situ by light-side biofilms through tightly coupled biotic interactions.

In conclusion, this study shows that the contribution of nitrification to $\mathrm{NH}_{4}^{+}$uptake at biofilm scale is shaped by the abundance, relative dominance and activity of AOA and $\mathrm{AOB}$, which are influenced by the environmental conditions where biofilms develop. In particular, at the habitat scale, either light avoidance (in the dark side of cobbles) or the sunshade protection by the biofilm structure (in the light side of cobbles) provide strategies that can counterbalance the negative effects of light on AO allowing their development and activity. Therefore, similar to algae, the activity of AO can also be ruled by light, although its consequences on stream nitrification rates could vary depending on the ecological and trophic interactions among microorganisms coexisting within the complex biofilm matrix.

\section{References}

APHA. 1995. Standard methods for the examination of water and wastewater. American Public Health Association.

Beman, J. M., B. N. Popp, and S. E. Alford. 2012. Quantification of ammonia oxidation rates and ammonia-oxidizing archaea and bacteria at high resolution in the Gulf of California and eastern tropical North Pacific Ocean. Limnol. Oceanogr. 57: 711-726. doi:10.4319/1o.2012.57.3.0711

Blainey, P. C., A. C. Mosier, A. Potanina, C. A. Francis, and S. R. Quake. 2011. Genome of a low-salinity ammoniaoxidizing archaeon determined by single-cell and metagenomic analysis. PLoS ONE 6: e16626. doi:10.1371/ journal.pone.0016626

Boston, H., and W. Hill. 1991. Photosynthesis-light relations of stream periphyton communities. Limnol. Oceanogr. 36: 644-656. doi:10.4319/1o.1991.36.4.0644

Church, M. J., B. Wai, D. M. Karl, and E. F. DeLong. 2010. Abundances of crenarchaeal amoA genes and transcripts in the Pacific Ocean. Environ. Microbiol. 12: 679-688. doi:10.1111/j.1462-2920.2009.02108.x
Cullen, J. J., X. Yang, and H. L. MacIntyre. 1992. Nutrient limitation of marine photosynthesis, p. 69-88. In P. G. Falkowski, A. D. Woodhead, and K. Vivirito [eds.], Primary productivity and biogeochemical cycles in the sea. Springer. Fernàndez-Guerra, A., and E. O. Casamayor. 2012. Habitatassociated phylogenetic community patterns of microbial ammonia oxidizers. PLoS ONE 7: e47330. doi:10.1371/ journal.pone.0047330 doi:10.1371/journal.pone.0047330

French, E., J. A. Kozlowski, M. Mukherjee, G. Bullerjahn, and A. Bollmann. 2012. Ecophysiological characterization of ammonia-oxidizing archaea and bacteria from freshwater. Appl. Environ. Microbiol. 78: 5773-5780. doi:10.1128/ AEM.00432-12

Gieseke, A., J. L. Nielsen, R. Amann, P. H. Nielsen, and D. De Beer. 2005. In situ substrate conversion and assimilation by nitrifying bacteria in a model biofilm. Environ. Microbiol. 7: 1392-1404. doi:10.1111/j.1462-2920.2005.00826.x

Guasch, H., and S. Sabater. 1995. Seasonal variations in photosynthesis-irradiance responses by biofilms in Mediterranean streams. J. Phycol. 31: 727-735. doi:10.1111/ j.0022-3646.1995.00727.x

Guerrero, M., and R. Jones. 1996. Photoinhibition of marine nitrifying bacteria. I. Wavelength dependent response. J. Mar. Ecol. Prog. Ser. 141: 193-198. doi:10.3354/meps141183

Herrmann, M., A. Scheibe, S. Avrahami, and K. Küsel. 2011. Ammonium availability affects the ratio of ammoniaoxidizing bacteria to ammonia-oxidizing archaea in simulated creek ecosystems. Appl. Environ. Microbiol. 77: 1896-1899. doi:10.1128/AEM.02879-10

Hooper, A. B., and K. R. Terry. 1974. Photoinactivation of ammonia oxidation in Nitrosomonas. J. Bacteriol. 119: 899-906.

Hyman, M. R., and D. J. Arp. 1992. 14C2H2- and 14CO2labeling studies of the de novo synthesis of polypeptides by Nitrosomonas europaea during recovery from acetylene and light inactivation of ammonia monooxygenase. J. Biol. Chem. 267: 1534-1545.

Kirchman, D. L. 1994. The uptake of inorganic nutrients by heterotrophic bacteria. Microb. Ecol. 28: 255-271. doi: 10.1007/BF00166816

Lipschultz, F., S. C. Wofsy, and L. E. Fox. 1985. The effects of light and nutrients on rates of ammonium transformation in a eutrophic river. Mar. Chem. 16: 329-341. doi: 10.1016/0304-4203(85)90054-4

Lipsewers, Y. A., N. J. Bale, E. C. Hopmans, S. Schouten, J. S. Sinninghe Damste, and L. Villanueva. 2014. Seasonality and depth distribution of the abundance and activity of ammonia oxidizing microorganisms in marine coastal sediments (North Sea). Front. Microbiol. 5: 472. doi: 10.3389/fmicb.2014.00472

Lock, M., R. Wallace, J. Costerton, R. Ventullo, and S. Charlton. 1984. River epilithon: Toward a structuralfunctional model. Oikos 42: 10-22. doi:10.2307/3544604

Martens-Habbena, W., P. M. Berube, H. Urakawa, R. José, and D. A. Stahl. 2009. Ammonia oxidation kinetics 
determine niche separation of nitrifying archaea and bacteria. Nature 461: 976-979. doi:10.1038/nature08465

Merbt, S. N., J.-C. Auguet, E. O. Casamayor, and E. Marti. 2011. Biofilm recovery in a wastewater treatment plantinfluenced stream and spatial segregation of ammoniaoxidizing microbial populations. Limnol. Oceanogr. 56: 1054-1064. doi:10.4319/lo.2011.56.3.1054

Merbt, S. N., D. A. Stahl, E. O. Casamayor, E. Martí, G. W. Nicol, and J. I. Prosser. 2012. Differential photoinhibition of bacterial and archaeal ammonia oxidation. FEMS Microbiol. Lett. 327: 41-46. doi:10.1111/j.1574-6968.2011.02457.x

Merbt, S., J.-C. Auguet, A. Blesa, E. Martí, and E. O. Casamayor. 2015. Wastewater treatment plant effluents change abundance and composition of ammoniaoxidizing microorganisms in Mediterranean urban stream biofilms. Microb. Ecol. 69: 66-74. doi:10.1007/s00248014-0464-8

Merseburger, G., E. Martí, and F. Sabater. 2005. Net changes in nutrient concentrations below a point source input in two streams draining catchments with contrasting land uses. Sci. Total Environ. 347: 217-229. doi:10.1016/ j.scitotenv.2004.12.022

Mußmann, M., and others. 2013. Colonization of freshwater biofilms by nitrifying bacteria from activated sludge. FEMS Microbiol. Ecol. 85: 104-115. doi:10.1111/1574-6941.12103

Nicol, G. W., S. Leininger, C. Schlepper, and J. I. Prosser. 2008. The influence of soil $\mathrm{pH}$ on the diversity, abundance and transcriptional activity of ammonia oxidizing archaea and bacteria. Environ. Microbiol. 10: 2966-2978. doi:10.1111/j.1462-2920.2008.01701.x

O'Brien, J. M., and W. K. Dodds. 2008. Ammonium uptake and mineralization in prairie streams: Chamber incubation and short-term nutrient addition experiments. Fresh. Biol. 53: 102-112. doi:10.1111/j.1365-2427.2007.01870.x

Ortiz-Alvarez, R., and E. O. Casamayor. 2016. High occurrence of Pacearchaeota and Woesearchaeota (Archaea superphylum DPANN) in the surface waters of oligotrophic high-altitude lakes. Environ. Microbiol. Rep. 8: 210217. doi:10.1111/1758-2229.12370

Pedneault, E., P. E. Galand, M. Potvin, J.-É Tremblay, and C. Lovejoy. 2014. Archaeal amoA and ureC genes and their transcriptional activity in the Arctic Ocean. Sci. Rep. 4: 4661. doi:10.1038/srep04661

Peterson, B. J., and others. 2001. Control of nitrogen export from watersheds by headwater streams. Science 292: 8690. doi:10.1126/science.1056874

Prosser, J., and G. Nicol. 2012. Archaeal and bacterial ammoniaoxidisers in soil: The quest for niche specialisation and differentiation. Trends Microbiol. 20: 523-531. doi: 10.1016/j.tim.2012.08.001

Restrepo-Ortiz, C. X., J.-C. Auguet, and E. O. Casamayor. 2014. Targeting spatiotemporal dynamics of planktonic SAGMGC-1 and segregation of ammonia-oxidizing thaumarchaeota ecotypes by newly designed primers and quantitative polymerase chain reaction. Environ. Microbiol. 16: 689-700. doi:10.1111/1462-2920.12191

Reuter, J. E., S. L. Loeb, and C. R. Goldman. 1986. Inorganic nitrogen uptake by epilithic periphyton in a N-deficient lake. Limnol. Oceanogr. 31: 149-160. doi:10.4319/ lo.1986.31.1.0149

Ribot, M., E. Martí, D. von Schiller, F. Sabater, H. Daims, and T. J. Battin. 2012. Nitrogen processing and the role of epilithic biofilms downstream of a wastewater treatment plant. Freshw. Sci. 31: 1057-1069. doi:10.1899/11-161.1

Ribot, M., D. von Schiller, M. Peipoch, F. Sabater, N. B. Grimm, and E. Martí. 2013. Influence of nitrate and ammonium availability on uptake kinetics of stream biofilms. Freshw. Sci. 32: 1155-1167. doi:10.1899/12-209.1

Risgaard-Petersen, N., M. H. Nicolaisen, N. P. Revsbeck, and B. A. Lomstein. 2004. Competition between ammonia oxidizing bacteria and benthic microalgae. Appl. Environ. Microbiol. 70: 5528-5537. doi:10.1128/AEM.70.9.5528-5537.2004

Roeselers, G., M. C. M. van Loosdrecht, and G. Muyzer. 2008. Phototrophic biofilms and their potential applications. J. Appl. Phycol. 20: 227-235. doi:10.1007/s10811-007-9223-2

Rotthauwe, J.-H., K.-P. Witzel, and W. Liesack. 1997. The ammonia monooxygenase structural gene amoA as a functional marker: Molecular fine-scale analysis of natural ammonia oxidizing populations. Appl. Environ. Microbiol. 63: 4704-4712.

Schön and Engel. 1962. Der Einfluss des Lichtes auf Nitrosomonas europaea Win. Arch. Microbiol. 42: 415-428.

Schramm, A., L. H. Larsen, N. P. Revsbech, N. B. Ramsing, R. Amann, and K. H. Schleifer. 1996. Structure and function of a nitrifying biofilm as determined by in situ hybridization and the use of microelectrodes. Appl. Environ. Microbiol. 62: 4641-4647.

Small, G. E., G. S. Bullerjahn, R. W. Sterner, B. F. N. Beall, S. Brovold, J. C. Finlay, R. M. L. McKay, and M. Mukherjee 2013. Rates and controls of nitrification in a large oligotrophic lake. Limnol. Oceanogr. 58: 276-286. doi:10.4319/ lo.2013.58.1.0276

Smith, J. M., F. P. Chavez, and C. A. Francis. 2014. Ammonium uptake by phytoplankton regulates nitrification in the sunlit ocean. PLoS One 9: e108,173. doi:10.1371/ journal.pone.0108173

Sonthiphand, P., E. Cejudo, S. L. Schiff, and J. D. Neufeld. 2013. Wastewater effluent impacts ammonia-oxidizing prokaryotes of the Grand River, Canada. Appl. Environ. Microbiol. 79: 7454-7465. doi:10.1128/AEM.02202-13

Strauss, E. A., and G. A. Lamberti. 2000. Regulation of nitrification in aquatic sediments by organic carbon. Limnol. Oceanogr. 45: 1854-1859. doi:10.1371/journal.pone. 0108173

Strauss, E. A., N. L. Mitchell, and G. A. Lamberti. 2002. Factors regulating nitrification in aquatic sediments: Effects of organic carbon, nitrogen availability, and $\mathrm{pH}$. Can. J. Fish. Aquat. Sci. 59: 554-563. doi:10.1139/f02-032 
Teissier, S., M. Torre, F. Delmas, and F. Garabétian. 2007. Detailing biogeochemical $\mathrm{N}$ budgets in riverine epilithic biofilms. J. NABS 26: 178-190. doi:10.1899/08873593(2007)26[178:DBNBIR]2.0.CO;2

Tourna, M., T. E. Freitag, G. W. Nicol, and J. I. Prosser. 2008. Growth, activity and temperature responses of ammoniaoxidizing archaea and bacteria in soil microcosms. Environ. Microbiol. 10: 1357-1364. doi:10.1111/j.14622920.2007.01563.x

Verhagen, F. J. M., and H. J. Laanbroek. 1991. Competition for ammonium between nitrifying and heterotrophic bacteria in dual energy-limited chemostats. Appl. Environ. Microbiol. 5: 3255-3263. doi:10.1371/ journal.pone.0108173

Vile, M. A., and others. 2014. N2-fixation by methanotrophs sustains carbon and nitrogen accumulation in pristine peatlands. Biogeochemistry 121: 317-328. doi:10.1007/ s10533-014-0019-6

Walker, C., and others. 2010. Nitrosopumilus maritimus genome reveals unique mechanisms for nitrification and autotrophy in globally distributed marine crenarchaea.
Proc. Natl. Acad. Sci. 107: 8818-8823. doi:10.1073/ pnas.0913533107

Zar, J. H. 1996. Biostatistical analysis. Prentice-Hall.

\section{Acknowledgments}

We thank Roser Ventosa for technical assistance at the Nutrient Analytical Service of the CEAB-CSIC and Dr H. Guasch for providing the LED panels. S.N.M. was supported by a JAE predoctoral fellowship from the Spanish National Research Council (CSIC) and S.B. by funding provided by the Spanish Research Council (JAE-DOC027) and the NICUS project (CGL2014-55234-JIN) from the Spanish Office for Research (MINECO). This research was granted by DARKNESS CGL2012-32747 to EOC and MED_FORESTREAM CGL2011-30590-CO2-02 (MINECO) and REFRESH244121 (7th Framework Programme EU Commission) to EM.

\section{Conflict of Interest}

None declared.

Submitted 23 March 2016 Revised 04 August 2016 Accepted 08 August 2016

Editor: Robert Howarth 